\title{
TRAP SPECTRA OF ANNEALED QUARTZ
}

\author{
A. Chruścińska, H.L. Oczkowski and K.R. Przegiętra \\ Institute of Physics, N. Copernicus University \\ Grudziądzka 5/7, 87-100 Toruń, Poland
}

(Received December 7, 1995)

\begin{abstract}
The trap energy density spectra of natural quartz were investigated by the fractional glow technique. The thermal treatment before excitation induces the changes of thermoluminescence sensitivity as well as the changes of trap spectrum. After annealing at temperature higher than $400^{\circ} \mathrm{C}$, a new kind of trap is observed. The frequency factor was determinated by the fitting of the theoretical glow curve calculated using the trap depth measured by fractional glow technique to experimental one.
\end{abstract}

PACS numbers: $78.60 . \mathrm{Kn}$

\section{Introduction}

Quartz - the mineral generally used in thermoluminescence (TL) dating is not yet entirely explored. The discussion about the only $100^{\circ} \mathrm{C}$ peak has been continued for tens of years $[1,2]$. Especially, the knowledge about trap depths $(E)$ as well as frequency factor $(s)$ in this mineral is not consolidated. Some papers concerning this problem present the results of rather casual investigations [3-7]. The experimental technique details are often insufficiently described for making any comparison between different results. The present level of knowledge in this field can be illustrated by the following statement originated from the paper concerning luminescence sensitivity changes in quartz due to annealing [8]. "It is to be mentioned finally that the parameters (e.g. $E$ and $s-$ note of author) values chosen for the model are not meant to be those of quartz, since these are unknown. They are chosen only for convenience in the calculations."

Some earlier papers already indicated that the TL properties of quartz depend strongly on the way it was treated before excitation $[2,9,10]$. The pre-dose effect in quartz is well known, as well as the influence of the thermal treatment of the mineral on the sensitivity changes caused by pre-irradiation.

This paper presents the dependence of energy density spectrum of traps (EDST) (actually the spectrum of traps filled during excitation) in natural quartz on thermal treatment before excitation. The temperature range of interest is between 100 and $350^{\circ} \mathrm{C}$ (when the normal glow curve is measured with heating rate about $\left.0.2^{\circ} \mathrm{C} / \mathrm{s}\right)$. 
It is obvious that samples have absorbed an unknown dose of irradiation before the experiments. Therefore, the fresh samples of synthetic quartz (produced by OMIG Poland) were used to check if the effects caused by prior radiation absorption are significant. If the results for the natural and synthetic material were alike, it would mean that the effects are mainly due to the thermal treatment. The next stage of experiments concerns an investigation of the EDST changes in quartz resulting from the thermal treatment after irradiation.

It has to be mentioned that the only method which allows to determine independently the EDST is the fractional glow technique (FGT) introduced by Gobrecht and Hofmann [11]. This method has been used with success in many investigations [12-15] and is constantly improved [16, 17]. It was also wrongly identified with initial rise method and as a consequence of this runs down in the way which cannot be accepted [18].

The FGT consists in registration of the TL intensity during both linear heating and cooling of the sample carried out in cyclic way. The sample heating from temperature $T_{1}$ to $T_{2}$ and subsequent cooling to temperature $T_{1}+\Delta T$ make one cycle. In the next cycle heating is carried out to temperature $T_{2}+\Delta T$ and cooling to temperature $T_{1}+2 \Delta T$. The characteristic assumption of this technique is that the trap population changes very little during one cycle. The fulfilment of this condition can be controlled by the comparison of the partial glow curves measured for heating and cooling in one cycle. There is a possibility to handle the value of $T_{2}-T_{1}$ and $\Delta T$ in order to keep the assumption valid during the experiment. The direct result of an experiment is the sequence of trap energies, $\langle E\rangle_{i}$ ( $i$ numbers the cycles), and integrals of the TL intensity, $L_{i}$, measured in the cycle. The trap depth is calculated separately for heating $\left(e_{i \mathrm{~h}}\right)$ and cooling $\left(e_{i \mathrm{c}}\right)$ by means of linear regression applied to dependencies

$$
\begin{aligned}
& {\left[\frac{\mathrm{d} \ln I}{\mathrm{~d}(1 / T)}\right]_{i \mathrm{~h}}=-\frac{e_{i \mathrm{~h}}}{k},} \\
& {\left[\frac{\mathrm{d} \ln I}{\mathrm{~d}(1 / T)}\right]_{i \mathrm{c}}=-\frac{e_{i \mathrm{c}}}{k},}
\end{aligned}
$$

where indexes " $\mathrm{h}$ " and "c" denote dependence and values obtained respectively for heating and cooling, $k$ - the Boltzmann constant, $I$ - the TL intensity, $T-$ the absolute temperature. The $\langle E\rangle_{i}$ is the mean of values $e_{i \mathrm{~h}}$ and $e_{i \mathrm{c}}$ taken with the factors dependent on the heating $\left(w_{i \mathrm{~h}}\right)$ and cooling $\left(w_{i \mathrm{c}}\right)$ rates in the cycle

$$
\langle E\rangle_{i}=e_{i \mathrm{~h}}+\frac{w_{i \mathrm{c}}}{w_{i \mathrm{~h}}+w_{i \mathrm{c}}}\left(e_{i \mathrm{c}}-e_{i \mathrm{~h}}\right) .
$$

The details of reasoning as well as the calculation leading to the above formula are presented in [17].

The experimental practice shows that the rates of the linear heating and cooling cannot be higher than $0.1^{\circ} \mathrm{C} / \mathrm{s}$ and $\mathrm{D} T$ should not be higher than $3^{\circ} \mathrm{C}$. This makes the average heating rate of the whole experiment to be lower than $0.005^{\circ} \mathrm{C} / \mathrm{s}$. The duration of measurement carried out to temperature $300^{\circ} \mathrm{C}$ is about 20 hours.

The EDST histograms are calculated using the distribution function [17]:

$$
H_{i}(E)=\frac{L_{i}}{\left|\langle E\rangle_{i-1}-\langle E\rangle_{i}\right|},
$$


where $H_{i}(E)$ denotes the relative number of traps of energy $E$ emptied during $i$-th cycle. The final EDST function $H(E)$ is calculated taking into consideration the possibility of overlapping of $H_{i}(E)$ obtained for different cycles.

\section{Experimental details}

To perform around hundred FGT experiments six bulks of quartz (Polish and Brazilian) were used. $0.4 \mathrm{~mm}$ thick slices cut perpendicularly to the $Z$ axis of the crystal and powder samples were prepared from all the bulks. In addition, samples of two different grain fractions of quartz from sediments (dune in Finland) were used for the investigation.

One part of the samples was annealed for 1 hour in air at $450^{\circ} \mathrm{C}$, the next at $750^{\circ} \mathrm{C}$ and the last one at $950^{\circ} \mathrm{C}$. Cooling was carried out during several hours in the oven. The fourth part of the samples, the "as-received" quartz, i.e. not annealed, was also used in experiments. All the samples were irradiated (about $50 \mathrm{kGy}$ gamma dose) and then the normal glow curves and the fractional glow technique measurements were carried out.

During all experiments samples (both powders and slices) were positioned right on the heating strip. The slices were pressed against the strip by a spring. The powder samples used in TL experiments were of about $15 \mathrm{mg}$ each, the amount usually used in TL dating. The normal glow curve was registered with constant heating rate $w=0.2^{\circ} \mathrm{C} / \mathrm{s}$. For a detailed description of our experimental setup the reader is referred to [19].

The EDST were obtained as the result of FGT carried out with the temperature jump between the cycles $(\mathrm{D} T)$ of $2^{\circ} \mathrm{C}$ (which makes the number of cycles in one experiment to be around 150$)$ and the heating amplitude $\left(T_{2}-T_{1}\right)$ varied in different experiments from 10 to $20^{\circ} \mathrm{C}$. The mean value of the heating and cooling rate were respectively 0.1 and $0.07^{\circ} \mathrm{C} / \mathrm{s}$ all over the cycles. The sample thermal contact with the heating strip was controlled by observation of the heating and cooling curve shape [11] during experiments.

\section{Results}

The first our observation, which is not surprising [29], is that the quartz annealed at 750 and $950^{\circ} \mathrm{C}$ gets smoky after irradiation. Samples annealed at $950^{\circ} \mathrm{C}$ are "more smoky" than those annealed at $750^{\circ} \mathrm{C}$. The smokiness disappears after TL measurements. The results of normal and fractional heating for this material are similar to the data obtained for as-received natural smoky quartz.

Figure 1 shows examples of normal glow curves of as-received (curves $d$ ) and annealed (curves $a, b, c-$ annealed respectively at $950,750,450^{\circ} \mathrm{C}$ ) quartz. It can be easily seen that the temperature $180^{\circ} \mathrm{C}$ divides the glow curves into two differently behaving parts. The shape of glow curves below $180^{\circ} \mathrm{C}$ is complicated and depends on the annealing temperature. Over $180^{\circ} \mathrm{C}$ there is one clear peak with a broad tail on the high temperature side arising after annealing. The sensitivity in this area increases much more than the sensitivity of the area below $180^{\circ} \mathrm{C}$. In the case of annealed sample Q5 (Fig. 1D), the high temperature tail is explicitly seen as a separate peak. 


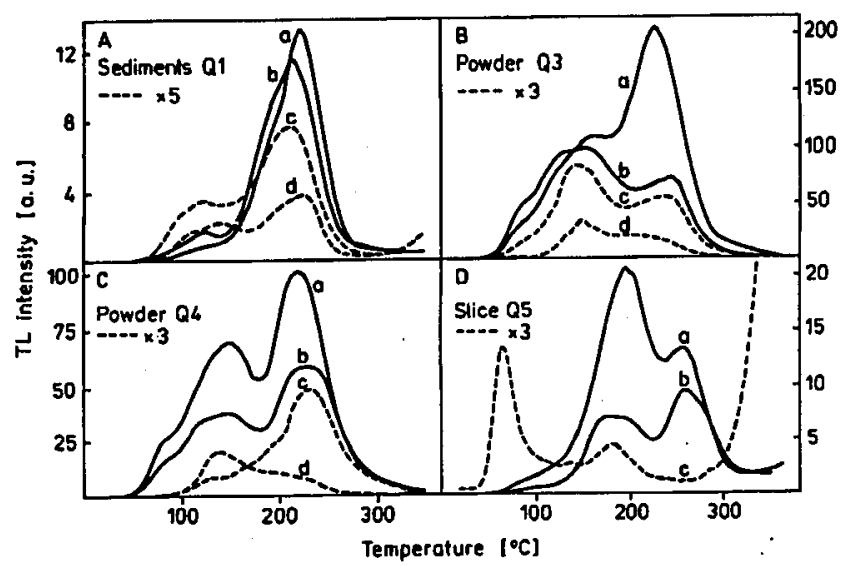

Fig. 1. The glow curves of quartz annealed at $950(a), 750(b), 450^{\circ} \mathrm{C}(c)$ and as-received $(d)$. The dashed line represents the TL intensity multiplied by coefficient. (A) Quartz separated from sediments (grain fraction $210 \mu \mathrm{m}$ ), (B) and (C) powder samples, (D) the slice sample.

Thermal treatment causes the same effects in synthetic as well as in natural quartz, therefore it can be assumed that the natural dose absorbed by the samples before experiments does not have a significant influence on the results,

Figure 2 shows how the traps are emptied during FGT procedure. The shaded area presents the $L_{i}$ dependence on the maximum temperature of the cycle. The curves reflect the changes of $\langle E\rangle_{i}$ during the experiment. These results are the basis for the EDST calculation. Some examples of the final histograms (related to Fig. 2) are presented in Fig. 3.

The EDST dependence on the temperature of the quartz annealing is demonstrated in Figs. 4-7. The gradual increase in the shallower trap density in the interval 1.1-1.4 eV and the translation of the lower limit of the trap depth occur. These shallow traps are not registered for the quartz which was not annealed (Fig. 3A, $3 \mathrm{~B}, 5 \mathrm{~A}, 6 \mathrm{~A})$. In this material the maximum of EDST is around $1.6 \mathrm{eV}(1.8 \mathrm{eV}$ for the powder - Fig. 5A, 6A). The number of the deeper traps of about $1.8 \mathrm{eV}$ increases after annealing at 750 and $950^{\circ} \mathrm{C}$ (Fig. 3C, D, 4C, D, 5C, D, 6D, 7B, C) and the EDST extends from 1.1 to $1.8 \mathrm{eV}(1.2-2.0 \mathrm{eV}$ for the powder - Fig. 5D, $6 \mathrm{D})$.

The results for the quartz separated from geological sediments (Fig. 1A and Fig. 4) differ from the results for the rest of investigated material. The TL sensitivity increases after annealing, however there is no significant difference between sensitivity of the material annealed at 750 and $950^{\circ} \mathrm{C}$ (Fig. $4 \mathrm{C}$ and D). The as-received geological samples have much richer structure of the EDST (Fig. 4A). The trap fraction of about $1.6 \mathrm{eV}$ does not dominate, while the shallower traps around $1.4 \mathrm{eV}$ have the highest concentration. The annealing causes also the density increase in the deeper traps of $1.8 \mathrm{eV}$.

The inverse trap depopulation - i.e. the emptying of shallower traps af- 


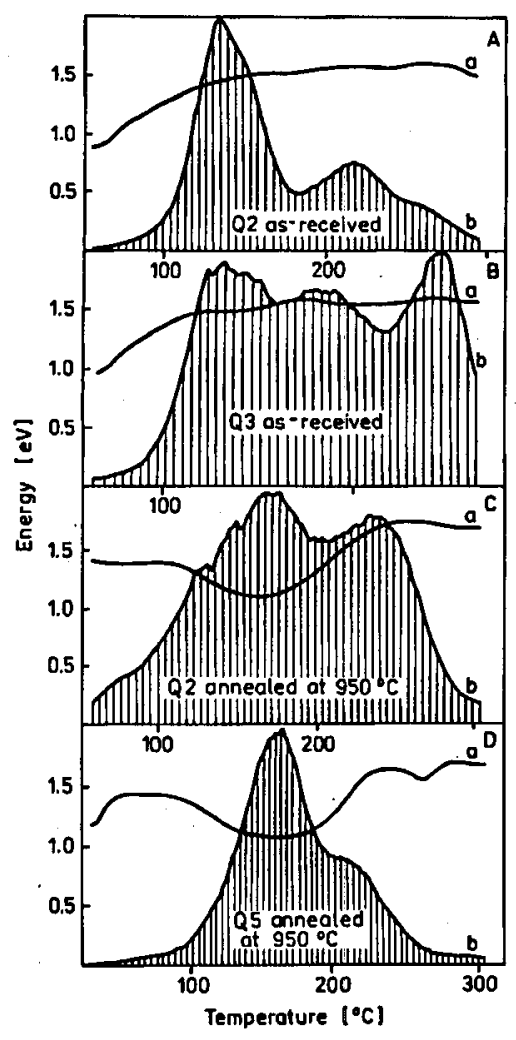

Fig. 2. The results of FGT experiments for quartz slices: curve $a$ is the averaged energy of traps emptied in $i$-th cycle $\left(\langle E\rangle_{i}\right)$ and curve $b$ - the light sum $\left(L_{i}\right)$ dependence on the maximum temperature in the cycle. (A) Q2 as-received, (B) Q3 as-received, (C) Q2 annealed at $950^{\circ} \mathrm{C}$, (D) Q5 annealed at $950^{\circ} \mathrm{C}$.

ter deeper ones caused by the correspondingly smaller value of frequency factor $s$ [15-17] — is observed during measurements carried out for annealed samples in which the shallow traps of the depth about $1.1 \mathrm{eV}$ appear (for example Fig. 2C and D). During the fractional heating, after emptying the traps of about $1.5 \mathrm{eV}$, lower traps are observed. Next, the trap energy increases again. The "valley" is not observed in as-received quartz (see Fig. 2A and B). The bars of EDST histograms around 1.1 (or $1.2 \mathrm{eV}$ for powders) for annealed samples correspond to this "valley". Its depth increases when the annealing temperature rises. The question is whether the thermal treatment continuously generates increasing number of monoenergetic traps or widens the trap distribution.

A brief review of the results allows one to notice that EDST obtained for powder samples is translated by about $0.1 \mathrm{eV}$ relative to the EDST of slices but the shape of the spectra and TL sensitivity of both kinds of samples are alike. The thermal contact of the polished slices with the heating strip is much better and stable. For this reason the results for slices are taken into consideration in 


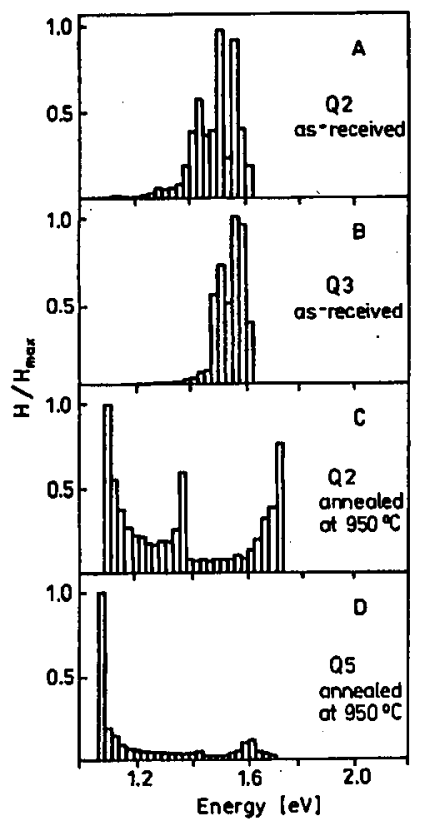

Fig. 3. The trap energy spectra for quartz slices obtained from the results presented in Fig. 2.

the quantitative discussion. The results for all the samples are used for qualitative estimation of the effects induced by the annealing.

\section{Discussion}

The results of computer simulations of the FGT experiments $[16,17,20,21]$ using the model of discrete trap levels show that the obtained EDSTs do not consist of discrete levels but narrow bands. Also, the traps having similar values of depth and/or very different concentrations disturb their determined energy values. One should recall that the energy calculated in the FGT cycle is an average energy of the traps emptied in the cycle. This means that not every bar of histogram represents the kind of traps actually existing in the crystal. Finally, it is common feature of the spectrometry.

The simplest way of testing if the EDST answers to the real traps, and simultaneously the way of the factor $s$ determination, is the glow curve calculation performed for the $E$ values taken from the measured EDST. The fitting procedure, under the assumption that the kinetic is of first order, runs as follows. First, taking the trap levels as discrete, one correlates each maximum of EDST with one peak of the experimental glow curve. The $s$ factor for each peak of glow curve is calculated using formula

$$
s_{n}=\frac{E_{n} w}{k T_{n}^{2}} \exp \left(\frac{E_{n}}{k T_{n}}\right)
$$

where $n=1,2 \ldots$ numbers the successive maxima of EDST, $E_{n}-$ the energy of $n$-th EDST maximum, $w$ - the linear heating rate during normal glow curve 

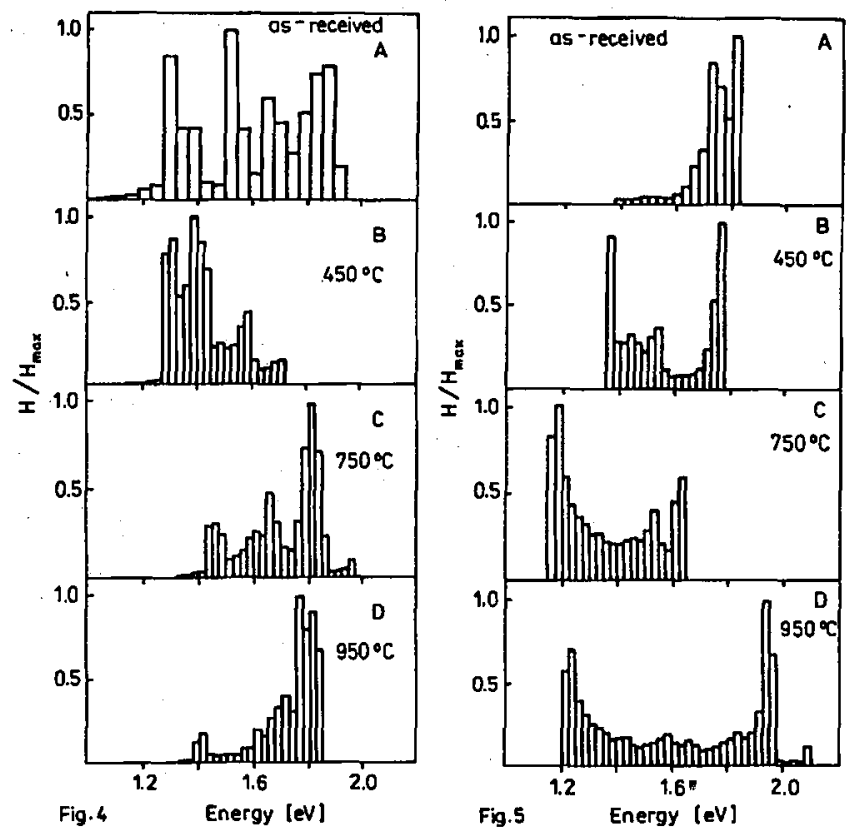

Fig. 4. The changes of the trap spectra due to the thermal treatment of quartz before the excitation. Sample Q1 separated from sediments. (A) Sample as-received, (B) sample annealed at $450^{\circ} \mathrm{C},(\mathrm{C})$ at $750^{\circ} \mathrm{C},(\mathrm{D})$ at $950^{\circ} \mathrm{C}$.

Fig. 5. The changes of the trap spectra due to the thermal treatment of quartz before the excitation. Powder sample of Q3. (A) Sample as-received, (B) sample annealed at $450^{\circ} \mathrm{C},(\mathrm{C})$ at $750^{\circ} \mathrm{C}$, (D) at $950^{\circ} \mathrm{C}$.

measurement, $T_{n}-$ the absolute temperature corresponding to the maximum of $n$-th glow peak.

Then the monomolecular glow curves, $I(T)$, for every EDST maximum are analytically calculated by means of the following polynomial approximation $[22,23]$ :

$$
I_{n}(x)=H_{n} s_{n} \exp \left[-x-l \frac{\mathrm{e}^{-x}}{x} \frac{a_{1} x+a_{2}}{x\left(x+b_{1}\right)+b_{2}}\right],
$$

where

$$
\begin{aligned}
& x=\frac{E_{n}}{k T}, \\
& l=\frac{E_{n} s_{n}}{k w},
\end{aligned}
$$

$a_{1}=0.995924, a_{2}=1.430913, b_{1}=3.330657, b_{2}=1.681534$ and $H_{n}$ - the initial trap population taken from EDST. The calculated glow curve is a sum of monomolecular curves, $I_{n}(T)$, determined for all the EDSTs maxima.

In the next stages, the bars neighbouring with the maxima of EDST are included with corresponding $s_{n}$ factors. The normal glow curves for those neighbouring with EDST maxima $E$ values are calculated using formula (6) and added 

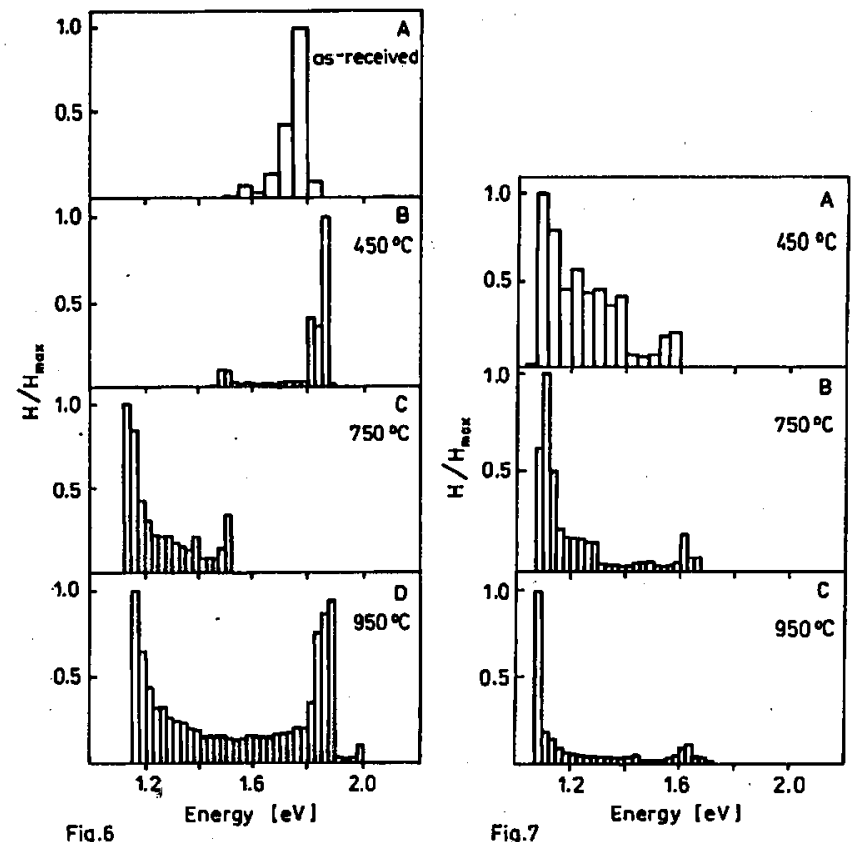

Fig. 6. The changes of the trap spectra due to the thermal treatment of quartz before the excitation. Powder sample of Q4. (A) Sample as-received, (B) sample annealed at $450^{\circ} \mathrm{C},(\mathrm{C})$ at $750^{\circ} \mathrm{C},(\mathrm{D})$ at $950^{\circ} \mathrm{C}$.

Fig. 7. The changes of the trap spectra due to the thermal treatment of quartz before the excitation. Slices of Q5. The TL intensity for Q5 as-received sample was too low for measuring the fractional glow curve. (A) Sample annealed at $450^{\circ} \mathrm{C}$, (B) at $750^{\circ} \mathrm{C}$, (C) at $950^{\circ} \mathrm{C}$.

to the curve $I(T)$ obtained in previous stage of the fitting. This step of procedure is repeated until the calculated $I(T)$ curve agrees with the experimental one.

The above method was used first for as-received quartz. As it was mentioned in the previous section, the EDSTs obtained for this material are surprisingly "poor" in comparison with registered glow curves. The final histograms for these samples do not allow to distinguish the actual number of maxima corresponding to the peak number of glow curve. In this situation, the graphs of the energy and light sum dependence on the cycle number (Fig. 2A and B) help to correlate the individual parts of EDST with the emission at definite temperature.

Figure 8 shows the fitting of experimental and theoretical glow curves for the as-received quartz. It turned out that some bars of EDST had to be divided between different TL peaks. As it can be seen, the fitting is satisfactory. It proves that the $s$ factor distribution is responsible for the complex shapes of as-received quartz TL curves. Its value is in the wide range $10^{16}-10^{13} \mathrm{~s}^{-1}$ for the trap depth in the range of $1.4-1.6 \mathrm{eV}$. 


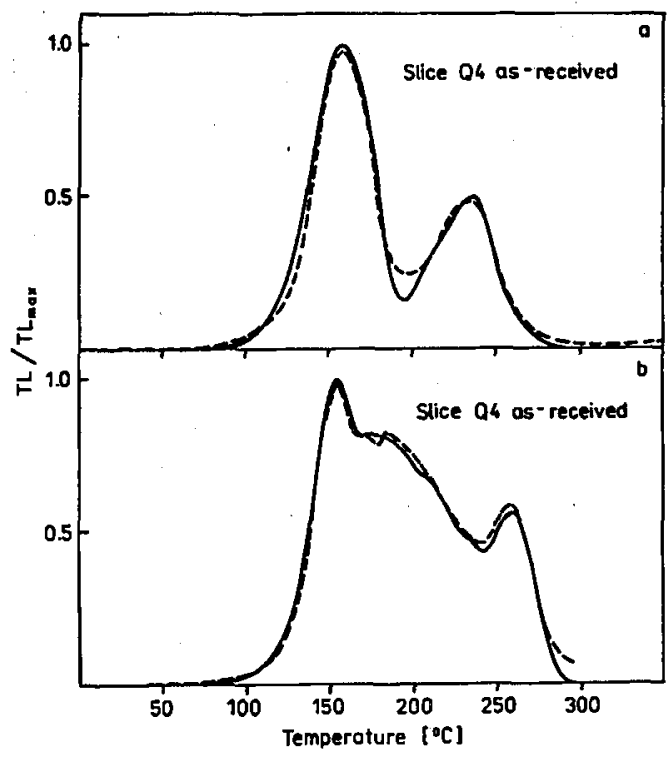

Fig. 8. The exemplary results of fitting procedure. The dotted curve is the experimental one and the solid curve is the theoretical one: (a) For the slice of Q2 $-E_{1}=1.45 \mathrm{eV}$, $s_{1}=1.4 \times 10^{15} \mathrm{~s}^{-1}, E_{2}=1.51 \mathrm{eV}, s_{2}=3 \times 10^{15} \mathrm{~s}^{-1}, E_{3}=1.56 \mathrm{eV}, s_{3}=2.9 \times 10^{14} \mathrm{~s}^{-1}$, $E_{4}=1.58 \mathrm{eV}, s_{4}=6 \times 10^{13} \mathrm{~s}^{-1}, E_{5}=1.61 \mathrm{eV}, s_{5}=2.2 \times 10^{13} \mathrm{~s}^{-1}$; (b) for the slice of $\mathrm{Q} 4-E_{1}=1.48 \mathrm{eV}, s_{1}=8.3 \times 10^{15} \mathrm{~s}^{-1}, E_{2}=1.51 \mathrm{eV}, s_{2}=3 \times 10^{15} \mathrm{~s}^{-1}, E_{3}=1.59 \mathrm{eV}$, $s_{3}=3.8 \times 10^{15} \mathrm{~s}^{-1}, E_{4}=1.55 \mathrm{eV}, s_{4}=4 \times 10^{14} \mathrm{~s}^{-1}, E_{5}=1.56 \mathrm{eV}, s_{5}=8.6 \times 10^{13} \mathrm{~s}^{-1}$, $E_{6}=1.60 \mathrm{eV}, s_{6}=1.7 \times 10^{13} \mathrm{~s}^{-1}$.

As it was mentioned above, the results of FGT for the samples annealed at $950^{\circ} \mathrm{C}$ demonstrate the inverse trap depopulation. During the fractional analysis the depopulation transition occurs from the traps of energy of about $1.5 \mathrm{eV}$ to the shallower traps of $1.1 \mathrm{eV}$. Then again the deeper levels are included in TL process. This effect can be seen in Fig. $2 \mathrm{C}$ and $\mathrm{D}$. In the graph the transition from the energy of $1.1 \mathrm{eV}$ to $1.6 \mathrm{eV}$ is smooth without marking any intermediate levels which are present in the EDST of as-received quartz (Fig. 2A and B).

The gap in the fitting in Fig. 9a shows that these traps (1.4-1.6 eV) still exist. In fact, when including them, the fitting gives satisfactory results (Fig. $9 \mathrm{~b}$ ). The traps from the range of 1.4-1.6 eV appear in the energy distribution of annealed quartz but they do not show up as separate bands because of their simultaneous depopulation with shallower or deeper traps having much more higher concentration.

The experience with the fitting for the samples annealed at $950^{\circ} \mathrm{C}$ makes us to pose a question before the analysis of the FGT results for the material annealed at the lower temperatures: does the annealing at a definite temperature lead to the occurrence of particular trap fraction? Or does the annealing temperature determine only the concentration of some traps?

The comparison of the EDSTs determined for the quartz samples annealed 


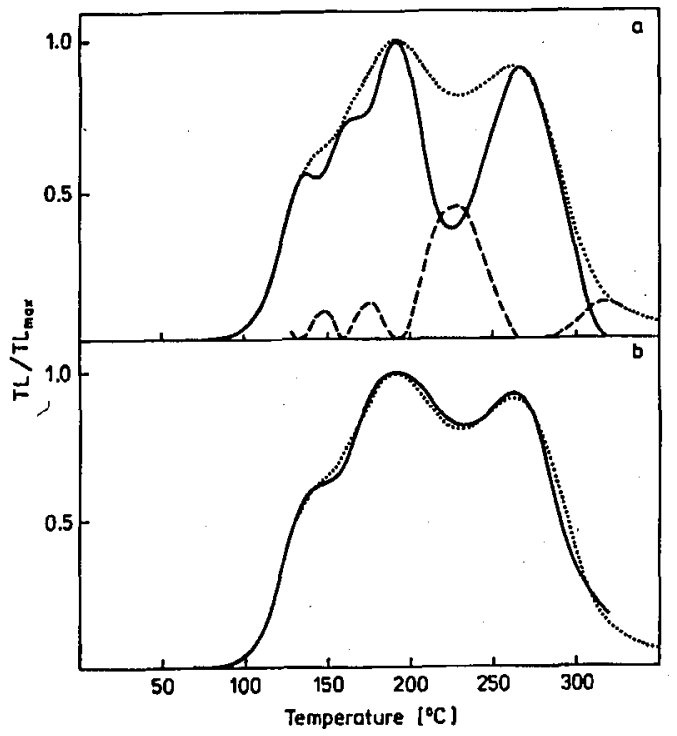

Fig. 9. The fitting procedure results for the slice of $\mathrm{Q} 2$ annealed at $950^{\circ} \mathrm{C}$. The pointed curve is the experimental one and the solid curve is the theoretical one. (a) In the theoretical curve plot only the trap depths obtained from FGT experiments were used. The dashed curve is the difference between theoretical and experimental curves. The trap parameters are: $E_{1}=1.41 \mathrm{eV}, s_{1}=3.3 \times 10^{15} \mathrm{~s}^{-1}, E_{2}=1.39 \mathrm{eV}, s_{2}=2.3 \times 10^{14} \mathrm{~s}^{-1}$, $E_{3}=1.10 \mathrm{eV}, s_{3}=1.8 \times 10^{10} \mathrm{~s}^{-1}, E_{4}=1.75 \mathrm{eV}, s_{4}=2.2 \times 10^{14} \mathrm{~s}^{-1}, E_{5}=1.70 \mathrm{eV}$, $s_{5}=2.7 \times 10^{13} \mathrm{~s}^{-1}$; (b) the above trap parameters determined separately for the sample Q2 annealed at $950^{\circ} \mathrm{C}$ and the as-received one (see Fig. 8a) were both used for the theoretical curve calculation.

at the same temperature confirms the latter. Although the annealing at higher temperatures and/or longer duration produces deeper "valley" as the result of inverse trap depopulation, there is no constant energy value connected with a particular thermal treatment. Depending on the quartz sample, the shallowest traps appear in the range from 1.1 to $1.5 \mathrm{eV}$ in EDST of the material annealed at $450^{\circ} \mathrm{C}$. In all the samples the annealing at $750^{\circ} \mathrm{C}$ involves in the EDST the traps of the depth of $1.1 \mathrm{eV}$. Simultaneously however, in some cases the deepest traps disappear. They do not disappear for samples in which the concentration of traps of $1.1 \mathrm{eV}$ is low.

We suggest that the annealing at $450^{\circ} \mathrm{C}$ creates the traps of the energy of $1.1 \mathrm{eV}$ in quartz. The histograms of some samples do not demonstrate the existence of these traps because of their low concentration in comparison with other defects. The maximum of EDST does not appear for $1.1 \mathrm{eV}$ but for the medium values between 1.1 and $1.5 \mathrm{eV}$. Its position depends on the ratio of the deeper to lower traps concentration. Likewise, the decrease in the maximum trap depth after the annealing at $750^{\circ} \mathrm{C}$ or at $450^{\circ} \mathrm{C}$ is caused rather by the high concentration of shallow traps than by the real absence of previously registered defects. The results of the experiments for all the samples confirm this hypothesis. 


\section{Conclusions}

Summing up, we can say that annealing at $T>450^{\circ} \mathrm{C}$ produces new defects creating the traps of $1.1 \mathrm{eV}$. The annealing at $950^{\circ} \mathrm{C}$ generates the traps of the depth of about $1.7 \mathrm{eV}$.

TABLE I

The parameters of traps in quartz obtained in result of FGT measurements analysis and fitting procedure described in the text. The ranges of $E$ and $s$ contain values determined for all investigated samples and take into account the experimental accuracy.

\begin{tabular}{|c|c|c|c|}
\hline $\begin{array}{c}\text { Peak position } \\
{\left[{ }^{\circ} \mathrm{C}\right]}\end{array}$ & $E[\mathrm{eV}]$ & $s\left[\mathrm{~s}^{-1}\right]$ & Comments \\
\hline 150 & $1.42-1.52$ & $1.5 \times 10^{15}-3.4 \times 10^{16}$ & \\
\hline 200 & $1.52-1.59$ & $2.5 \times 10^{14}-1.5 \times 10^{15}$ & \\
\hline 200 & $1.08-1.13$ & $2.0 \times 10^{9}-2.5 \times 10^{10}$ & $\begin{array}{l}\text { generated by the } \\
\text { annealing at } T>450^{\circ} \mathrm{C}\end{array}$ \\
\hline 260 & $1.54-1.64$ & $4.6 \times 10^{12}-4.3 \times 10^{13}$ & \\
\hline 270 & $1.67-1.77$ & $4.2 \times 10^{13}-3.7 \times 10^{14}$ & $\begin{array}{l}\text { generated by the } \\
\text { annealing at } T>700^{\circ} \mathrm{C}\end{array}$ \\
\hline
\end{tabular}

Table I contains the trap parameters responsible for the TL in the range $100-350^{\circ} \mathrm{C}$ determined for the slices of as-received quartz and annealed at $950^{\circ} \mathrm{C}$. The accuracy of energy values obtained as the result of FGT measurements $(\Delta E)$ was taken into account in the determination of presented energy ranges. The $s$ factors are the results of fitting procedures for the extreme energy values $E-\Delta E$ and $E+\Delta E$ for each $E$. The ranges in Table I contain the values determined for all investigated samples.

It should be stressed that the accuracy of the energy determination in FGT experiments is not better than $25 \mathrm{meV}$. Taking this into consideration we limit ourselves to propose some ranges for $E$ and $s$ values. These results are obtained on the basis of the simplest model of TL kinetics - the first order one. But the convergence of the calculated curves with the experimental results proves the statement that the kinetics of TL in quartz is governed by the monomolecular process [24].

Considering the TL dating, it is convenient to present the data from Table I as a carrier lifetime in the trap

$$
\tau=\frac{1}{s} \exp \left(\frac{E}{k T}\right)
$$

Table II contains the calculated positions of peaks presented in Table I for heating rate of $10^{\circ} \mathrm{C} / \mathrm{s}$, usually applied in TL dating. The lifetime values show that the region over $300^{\circ} \mathrm{C}$ (for heating rate $10^{\circ} \mathrm{C} / \mathrm{s}$ ) is safe for archaeodose determination. The component of $270^{\circ} \mathrm{C}$ peak originated from the shallow traps of 


\section{TABLE II}

The data useful for TL dating. The carrier lifetime in the traps whose parameters are presented in Table $\mathrm{I}$. The peak positions in the second column are for the heating rate of $10^{\circ} \mathrm{C} / \mathrm{s}$.

\begin{tabular}{c|c|c}
\hline \hline \multicolumn{2}{c|}{ Peak position $\left[{ }^{\circ} \mathrm{C}\right]$} & \multirow{t}{*}{ [years] for $T=20^{\circ} \mathrm{C}$} \\
\cline { 1 - 2 }$w=0.2^{\circ} \mathrm{C} / \mathrm{s}$ & $w=10^{\circ} \mathrm{C} / \mathrm{s}$ & \\
\hline 150 & 190 & $56-131$ \\
200 & 250 & $1.7 \times 10^{4}-4.7 \times 10^{4}$ \\
200 & 270 & $35-60$ \\
260 & 320 & $2.1 \times 10^{6}-12 \times 10^{6}$ \\
270 & 330 & $0.4 \times 10^{8}-2.4 \times 10^{8}$
\end{tabular}

about $1.1 \mathrm{eV}$ causes the quick decay of $\mathrm{TL}$ below $300^{\circ} \mathrm{C}$. It should be stressed that if the powder samples were not put directly onto the heating strip but in the cup, as it is usually during dating measurements, the glow curves can be shifted even more to higher temperatures.

Finally, it should be noted that the changes of trap spectrum due to thermal treatment can be used as a test of the ceramics usefulness to the TL dating. Quartz grains separated from ceramics which was not sufficiently fired do not manifest the existence of shallow traps and the inverse trap depopulation during FGT experiment.

It is interesting in this place to mention the paper [8] which attributes the increase in TL sensitivity after annealing to the enhanced recombination centres concentration or to the removal of non-luminescence centres due to annealing. However, the presented results of FGT measurements clearly show that after annealing we have to do with a new kind of trap and the authors of [8], as they admit, do not know the depth of traps involved in the phenomenon which they describe. This inconsistency in explanation of the effect of TL and optically stimulated luminescence (OSL) sensitivity changes in annealed quartz should be removed in future by detailed quantitative comparison of the result of EDST, ESR and radioluminescence measurements.

It can be noted that the presented results for not annealed, separated from the sediments quartz are in good agreement with the data presented in [6].

The glow curves for quartz samples which were annealed at $450^{\circ} \mathrm{C}$ after irradiation (100 kGy) or which were doped with lithium and sodium [25] have their shapes like presented in this paper for samples annealed at $950^{\circ} \mathrm{C}$. Hence, it is possible that the annealing generates defects containing ions $\mathrm{Li}^{+}$and $\mathrm{Na}^{+}$. They are freed from other defects during annealing and strong irradiation accelerates this process. The known centres with $\mathrm{Li}^{+}$and $\mathrm{Na}^{+}\left[\mathrm{Ge}(\mathrm{C}, \mathrm{A})_{\mathrm{e}^{-}} / \mathrm{Li}^{+}\right],\left[\mathrm{Ge}(\mathrm{A})_{\mathrm{e}^{-}} / \mathrm{Na}^{+}\right]$ (A and $\mathrm{C}$ denote different Ge positions in the quartz lattice) [26] or [ $\left[\mathrm{Ge}_{\mathrm{e}}-/ \mathrm{NaMN}\right.$ ] where $\mathrm{M}, \mathrm{N}=\mathrm{Li}^{+}$or $\mathrm{Na}^{+}[27]$ are suggested to be responsible for the TL in the range over $180^{\circ} \mathrm{C}$. 
Since the germanium centres with incorporated alkali metal ions are known to decay in the range of $200-450^{\circ} \mathrm{C}$, it can be expected that the annealing does not produce these centres directly but generates defects which keep the alkaline ions till the irradiation. The most common defects which can play this role are centres $\mathrm{Al}-\mathrm{M}^{+}$, which disappear during the irradiation at room temperature. The increasing concentration of these centres can be explained by the change of $\mathrm{Al}-\mathrm{OH}$ centres to $\mathrm{Al}-\mathrm{M}^{+}$during annealing at temperatures higher than $330^{\circ} \mathrm{C}$ [28]. Unfortunately, there is still no answer to the question where the alkali metal ions are localized before this annealing.

On the basis of the literature data and the results of presented investigations one can formulate a hypothesis that the annealing enlarges the number of the centres which become the source of the alkali metal ions during the irradiation. These ions diffuse through the crystal during the excitation and are attached to the defect creating the traps. The more alkaline ions, the greater concentrations and variety of traps.

\section{Acknowledgments}

We would like to thank Dr. S. Truszkowski and eng. M. Kowal of the Institute of Chemistry of $\mathrm{N}$. Copernicus University for giving us the possibility of using the gamma source for the excitation. This work was supported by the Committee for Scientific Research project 2 P302 18604.

\section{References}

[1] J. Zimmermann, J. Phys. C, Solid State Phys. 4, 3265 (1971).

[2] X.H. Yang, S.W.S. McKeever, J. Phys. D, Appl. Phys. 23, 237 (1990).

[3] R.G. Schwartzmann, J.A. Kierstead, P.W. Levy, Journal of the European Study Group on Physical, Chemical and Mathematical Techniques Applied to Archaeology 9, 163 (1983).

[4] P.L. Kaipa, E.H. Haskell, Nucl. Tracks 10, 621 (1985).

[5] A. Delunas, V. Maxia, G. Spano, Phys. Scr. 37, 608 (1988).

[6] T. Hashimoto, M. Kojima, N. Shiraj, M. Ichino, Nucl. Tracks 21, 217 (1993).

[7] A.G. Wintle, Geophys. J. R. Astr. Soc. 41, 107 (1975).

[8] L. Botter-Jensen, N. Agersnap Larsen, V. Mejdahl, N.R.J. Poolton, M.F. Morris, S.W.S. McKeever, Radiat. Meas. 24, 535 (1995).

[9] M. David, C.M. Sunta, A.K. Ganguly, Indian J. Pure Appl. Phys. 15, 201 (1977).

[10] M. David, C.M. Sunta, Nucl. Tracks 10, 625 (1985).

[11] H. Gobrecht, D. Hofmann, J. Phys. Chem. Solids 27, 509 (1966).

[12] W.G. Bula, I.A. Tale, Proc. Sov. Acad. Sci. Ser. Fiz. 38, 1277 (1974).

[13] H.L. Oczkowski, J. Lumin. 17, 113 (1978).

[14] H.L. Oczkowski, Phys. Status Solidi A 68, 199 (1981).

[15] I.A. Tale, Nucl. Tracks 21, 65 (1993).

[16] I.A. Tale, Phys. Status Solidi A 66, 65 (1981).

[17] A. Chruścińska, J. Lumin. 62, 115 (1994). 
[18] J.A. Kierstead, P.W. Levy, Nucl. Tracks 18, 19 (1991).

[19] A. Pietkun, L. Polakiewicz, H.L. Oczkowski, Acta Phys. Pol. A 81, 687 (1992).

[20] H.L. Oczkowski, Acta Phys. Pol. A 76, 649 (1989).

[21] F. Firszt, H.L. Oczkowski, Phys. Status Solidi A 111, 113 (1989).

[22] H.L. Oczkowski, Phys. Status Solidi A 74, 65 (1982).

[23] H.L. Oczkowski, C. Koefle, Acta Phys. Pol. A 67, 907 (1984).

[24] S.W.S. McKeever, Thermoluminescence of Solids, Cambridge University Press, Cambridge 1985.

[25] M.G. Jani, L.E. Halliburton, E.E. Kohnke, J. Appl. Phys. 54, 6321 (1983).

[26] A. Halperin, J.E. Ralph, J. Chem. Phys. 39, 63 (1963).

[27] R.V. Lorenze, F.J. Fiegl, Phys. Rev. B 8, 4833 (1973).

[28] L.E. Halliburton, N. Koumvakalis, M.E. Markes, J.J. Martin, J. Appl. Phys. 52, 3565 (1981).

[29] M.C.M. O'Brien, Proc. R. Soc. Lond. A 231, 404 (1945). 